\title{
İdrar yolu enfeksiyonlarından izole edilen Pseudomonas Aeruginosa'larda antibiyotik direnci.
}

\section{The antibiotic resistance in Pseudomonas Aeruginosas isolated from urinary tract infections}

\author{
Halil ER ${ }^{1}$, Merve ŞEN ${ }^{1}$, Mustafa ALTINDiş² \\ 'Afyon Kocatepe Üniversitesi, Tıp Fakültesi, Mikrobiyoloji Anabilim Dalı, Afyon, \\ ${ }^{2}$ Sakarya Üniversitesi, Tıp Fakültesi, Mikrobiyoloji Anabilim Dalı, Sakarya, TÜRKIYE
}

\section{ÖZET}

Amaç: Dünya'da ve ülkemizde Pseudomonas aeruginosa enfeksiyonları önemli bir problem haline gelmiştir. P. aeruginosa çoğunlukla nozokomiyal enfeksiyon etkeni olarak karşımıza çıkmaktadır. Üriner sistemin anatomik defektleri veya üriner sisteme girişimsel uygulamalar P. aeruginosa enfeksiyonu gelişme riskini artırmaktadır. Üriner sistemin enfeksiyonları aynı zamanda hayatı tehdit eden ürosepsis tablosunun gelişmesine neden olabilmektedir. Bu çalışmada hastanede yatan hastalardan idrar yolu enfeksiyonu etkeni olarak izole edilen P. aeruginosa suşlarının yıllara göre değişen antibiyotik direnç profilleri incelenmiştir.

Gereç ve Yöntemler: Çalışmaya 2008-2012 yılları arasında hastanede yatmakta olan hastalardan idrar yolu enfeksiyonu etkeni olarak izole edilen 103 P. aeruginosa dahil edilmiştir. Suşların identifikasyon ve antibiyogram çalışmaları konvansiyonel yöntemler ve otomatize sistemle (Phoenix, BD, USA) gerçekleştirilmiştir.

Bulgular: Çalışmalar sonucunda en yüksek direnç oranı seftazidim $(\% 85,4)$ ve piperesilin/tazobaktama $(\% 86,6)$ karşı tespit edilmiştir. Az sayıda izolatta karbapenem direnci $(\% 20,4)$ saptanmıştır. Sefepim $(\% 46,7)$ ve levofloksasin $(\% 41,8)$ için orta düzey direnç saptanmıştır. Ayrıca üç hastada idrar yolu enfeksiyonu etkeni olarak saptanan P. aeruginosa izolatına benzer direnç paternine sahip izolatlar hastaların kan kültüründen de izole edilmiştir. Bu izolatlar ürosepsis etkeni olarak değerlendirilmiştir.

Sonuçlar: P. aeruginosa izolatlarının etken olduğu idrar yolu enfeksiyonların tedavisinde kullanılabilecek antibiyotiklerin büyük çoğunluğuna karşı direnç gelişiminin hızla arttığı görülmüştür.

Anahtar Kelimeler: İdrar yolu enfeksiyonları, Pseudomonas aeruginosa, antibiyotik direnci, ürosepsis.

\footnotetext{
Sorumlu Yazara: Halil Er, M.D. Sakarya Üniversitesi Tıp Fakültesi, Tıbbi Mikrobiyoloji Anabilim Dalı, 71450,

Sakarya, TURKEY

Telefon: 00905326615263 e-posta: haliler004@hotmail.com

Received: 16.04.2015 Accepted: 04.08.2015

doi: $10.18663 / \mathrm{tjcl} .26388$

Bu makale EKMUD 2013 Bilimsel Platformu 2013, Antalya'da yazılı poster olarak sunulmuştur.
} 


\begin{abstract}
Aim: Pseudomonas aeruginosa infections have become a major problem in the world and in our country. P. aeruginosa is often encountered as a nosocomial infection. Anatomical defects of the urinary tract or urinary tract interventional applications increases the development of P. aeruginosa infection. Urinary tract infection can also lead to the development of life-threatening sepsis. In this study, we investigated the change of antibiotic resistance profiles of P.aeruginosa strains isolated from hospitalized patients as a urinary tract infection by the years.
\end{abstract}

Material and Methods: This study includes 103 P. aeruginosa strains isolated from hospitalized patients with urinary tract infection between the years 2008-2012. Identification and antibiotic susceptibility studies of the strains were performed by conventional methods and automated systems (Phoenix, BD, USA).

Results: Maximum resistance was shown to ceftazidime (85.4\%), and Piperacillin/Tazobactam (86.6\%). Moderate resistance was observed against cefepime (46.7\%) and levofloxacin (41.8\%). However, least number of isolates showed resistance against carbapenems (20.4\%). P. aeruginosa isolates from three urinary tract infection patients with similar resistance patterns were also isolated from their blood cultures. Therefore the isolates were evaluated as sepsis factors.

Conclusion: This study showed that most P. aeruginosa strains causing urinary tract infections gain rapidly increasing resistance to the majority of antibiotics used in the treatment.

Keywords: Urinary tract infections, Pseudomonas aeruginosa, Antibiotic resistance rates, Urosepsis

\section{Giriş}

Pseudomonas aeruginosa gram negatif, hareketli, oksidaz pozitif ve zorunlu aerob bir basil olup yüksek morbidite ve mortalite ile seyreden ciddi hastane enfeksiyonlarına neden olabilir [1]. P. aeruginosa, özellikle savunma mekanizmalarının zayıfladığı immün yetmezlik durumlarında, malign ve metabolik hastalığı bulunanlarda, uzun süreli kemoterapi ve radyoterapi alanlarda, yaşlılarda ve ağır yanık durumlarında enfeksiyonlara sebep olabilen önemli bir patojendir [2]. P. aeruginosa nedenli üriner sistem enfeksiyonları çoğunlukla kateter gibi yabancı cisim varlığı ve idrar akımındaki bozukluk sonucu oluşmaktadır [3]. "Quorum sensing" Enfeksiyonun patogenezinde pek çok virülans faktörünün yanında, biyofilm oluşumu ve önemli rol oynar [4]. Enfeksiyonun lokalize ya da sistemik tutulumuna bağlı olarak üriner sistem enfeksiyonları bakteriüri, sepsis, ağır sepsis ya da septik şoka kadar uzanan geniş bir klinik yelpazeye sahiptir [5].

Kadınların yaklaşık \%10-35'i yaşamının bir döneminde üriner sistem enfeksiyonu geçirmekte ve \%50'sinde enfeksiyon yenilenmektedir. İleri yaşlarda üriner sistem enfeksiyon prevalansı artmakta, kadınların \%20-30'unda bakteriüri görülmektedir [6-8]. Toplum kaynaklı ürosepsiste en sık etken Escherichia coli iken, nozokomiyal ürosepsiste, her hastaneye göre değişmekle birlikte, P. aeruginosa, S. epidermidis ve kandidalar etken olarak karsımıza çıkmaktadır $[9,10]$. Altta yatan morbit hastalık, ileri yaş, diyabet, üremi, şuur bozukluğu, üriner kateter kullanımı, üriner sistem anomalisi, üriner sistemde taş, nörojenik mesane, immünsupressif tedavi, antibiyotik kullanımı, uzun süre hastanede yatma ürosepsise predispozan faktörler olarak karşımıza çıkmaktadır [11,12].

P. aeruginosa enfeksiyonlarında kullanılan antibiyotiklere zaman içinde direnç gelişmekte ve bazı durumlarda tedavi sırasında bile duyarlılık durumu değişebilmektedir. Direnç gelişimi özellikle spesifik antibiyotik kullanımından sonra gelişmekte ve hastadan hastaya dirençli suşlar geçebilmektedir [13]. Tedavide kullanılan çeşitli antibiyotiklere karşı gelişen dirençlerin bir araya gelmesi ve antibiyotikler arasında çapraz direnç gelişimi, çoklu antibiyotik direnci (ÇAD) sorununu ortaya çıkarmaktadır [13]. P. aeruginosa suşlarının antibiyotiklere dirençli olmasının hastanede kalış süresi, tedavi maliyeti ve mortalite üzerine olumsuz etkisi görülmektedir [14,15]. Uygun olmayan antibakteriyel ajanların kullanımı nedeniyle giderek artan direnç, oluşan enfeksiyonların tedavisinde ciddi problemler oluşturmaktadır [16]. Bu çalışmada hastaneden idrar yolu enfeksiyonu olarak izole edilen P. aeruginosa suşlarının yıllara göre değişen antibiyotik direnç profilleri incelenmiştir.

\section{Yöntem ve Gereçler}

Çalışmamıza 2008-2012 yılları arasında hastanede yatmakta olan hastalardan idrar yolu enfeksiyonu etkeni olarak izole edilen 103 P. aeruginosa örneği dahil edilmiş bu suşların antibiyotik duyarlılıkları retrospektif olarak taranmıştır. Ayrıca sepsis kliniği gösteren hastalardan alınan kan kültürleri incelenmiş ve aynı direnç paternine sahip P. aeruginosa izolatları ürosepsis etkeni olarak değerlendirilmiştir.

İdrar kültürü için uygun şekilde alınan idrar (gerekli temizlik yapıldıktan sonra orta idrar; sondalı hastalar için, sterilizasyon kurallarına dikkat edilerek alınan idrar örneği) laboratuvarda bekletilmeden kanlı agar, eosin methylene blue (EMB) agara $0,01 \mathrm{ml}$ hacimli standart öze ile ekilmiştir. Etüvde $35-37^{\circ} \mathrm{C}^{\prime} \mathrm{de}$ 18-24 saat inkübasyona bırakılarak üreyen bakteriler değerlendirmeye alınmıştır [17]. Bakterilerin identifikasyonu konvansiyonel yöntemler ve otomatize sistemlerle (Phoenix, BD,USA) yapılmıştır [18]. 
Kan kültürü için hastadan uygun koşullarda deri antisepsisi sağlanarak vacutainer yardımı ile BACTEC 9120 (Becton Dickinson) şişelerine alınarak, özel otomatik kan kültürü cihazına yerleştirilmiştir. Pozitif sinyal veren şişeler vakit kaybetmeden kanlı agar, eosin methylene blue agar, çikolatamsı agara pasaj yapılarak $18-24$ saat $35-37^{\circ} \mathrm{C}^{\prime} \mathrm{de}$ inkübasyona bırakılmıştır. Üreyen bakteriler konvansiyonel yöntemler ve otomatize sistemlerle identifiye edilmiştir [18].

Suşların in-vitro antibiyotik duyarlılıkları, Clinical Laboratory Standards Institute önerilerine uygun olarak MuellerHinton besiyerinde BD Phoenix sistemi ve Kirby-Bauer disk difüzyon yöntemiyle çeşitli antibiyotik diskleri kullanılarak değerlendirilmiştir [19].

\section{Bulgular}

Çalışmaya dahil edilen örneklerin 68'i (\%66) bayan hastadan, 35'i (\%34) erkek hastadan izole edilmiştir. İzole edilen 103 P.aeruginosa örneğinden 67'si (\%65) dahili birimlerde yatan hastalardan, 36'ü (\%35) ise cerrahi birimlerde yatan hastalardan izole edilmiştir. Seftazidim ve piperasilin/ tazobaktam en dirençli antibiyotikler olarak tespit edilirken, az sayıda izolatta karbapenem direnci saptanmıştır (Tablo 2). Ayrıca üç hastada idrar yolu enfeksiyonu olarak saptanan P. aeruginosa izolatına benzer direnç paternine sahip izolatlar hastaların kan kültüründen de izole edilmiştir. Bu izolatlar ürosepsis etkeni olarak değerlendirilmiştir.

Tablo 1. İdrar kültüründe P. aeruginosa üreyen hastaların yaş ve cinsiyet dağılımları

\begin{tabular}{|l|c|c|c|c|c|c|}
\hline & $0-5$ yaş & $6-18$ yaş & $19-40$ yaş & $40-60$ yaş & 61 yaş üstü & Toplam \\
\hline Erkek & 4 & 8 & 2 & 2 & 19 & 35 \\
\hline Kadın & 7 & 4 & 9 & 21 & 27 & 68 \\
\hline Toplam & 11 & 12 & 11 & 23 & 46 & 103 \\
\hline
\end{tabular}

Tablo 2. Antibiyotiklerin direnç oranlarındaki yıllara göre değişim

\begin{tabular}{|l|c|c|c|c|c|c|}
\hline & $\begin{array}{c}2008 \\
\mathrm{n}: 17(\%)\end{array}$ & $\begin{array}{c}2009 \\
\mathrm{n}: 21(\%)\end{array}$ & $\begin{array}{c}2010 \\
\mathrm{n}: 21(\%)\end{array}$ & $\begin{array}{c}2011 \\
\mathrm{n}: 14(\%)\end{array}$ & $\begin{array}{c}2012 \\
\mathrm{n}: 30(\%)\end{array}$ & $\begin{array}{c}\text { Toplam } \\
\mathrm{n}: 103(\%)\end{array}$ \\
\hline Seftazidim & $14(82,3)$ & $18(85,7)$ & $20(95,2)$ & $11(78,5)$ & $25(83,3)$ & $88(85,4)$ \\
\hline Gentamisin & $8(47,0)$ & $9(42,8)$ & $7(33,3)$ & $3(21,4)$ & $7(23,3)$ & $34(33,0)$ \\
\hline Torbamisin & $9(52,9)$ & $7(33,3)$ & $4(19,0)$ & $1(7,1)$ & $2(6,6)$ & $23(22,3)$ \\
\hline Amikasin & $1(5,8)$ & $7(33,3)$ & $3(14,3)$ & $1(7,1)$ & $4(13,3)$ & $16(15,5)$ \\
\hline Sefepim & $11(64,7)$ & $12(57,1)$ & $9(42,8)$ & $2(14,3)$ & $11(36,6)$ & $45(46,7)$ \\
\hline Siprofloksasin & $8(47,0)$ & $9(42,8)$ & $3(14,3)$ & $1(7,1)$ & $12(40,0)$ & $33(32,0)$ \\
\hline Levofloksasin & $7(41,1)$ & $9(42,8)$ & $8(38,1)$ & $5(35,7)$ & $14(46,6)$ & $43(41,8)$ \\
\hline Imipenem & $4(23,5)$ & $5(23,8)$ & $3(14,3)$ & $5(35,7)$ & $4(13,3)$ & $21(20,4)$ \\
\hline Meropenem & $7(41,1)$ & $4(19,0)$ & $3(14,3)$ & $4(28,5)$ & $6(20,0)$ & $24(23,3)$ \\
\hline Tazobaktam/piperasilin & $15(88,2)$ & $21(100,0)$ & $20(95,2)$ & $11(78,5)$ & $22(73,3)$ & $89(86,6)$ \\
\hline Ofloksasin & $5(29,4)$ & $6(28,5)$ & $5(23,8)$ & $3(21,4)$ & $7(23,3)$ & $26(25,2)$ \\
\hline
\end{tabular}

\section{Tartışma}

İdrar yolu enfeksiyonlarında en sık izole edilen mikroorganizmalar, Escherichia coli, Proteus mirabilis, Pseudomonasaeruginosa, Klebsiella pneumonia, Enterococcus faecalis ve özellikle genç kadınlarda Staphylococcus saprophyticus'tur [20]. P. aeruginosa hastane kökenli idrar yolu enfeksiyonlarının üçüncü en sık nedenlerindendir [16]. Hastane kaynaklı Pseudomonas enfeksiyonlarında bu enfeksiyonların tedavisinde sık kullanılan anti-pseudomonal antibiyotiklere karşı direnç artışı görülmektedir. Üçüncü kuşak sefalosporinlerin hastanelerde yaygın kullanımı ile artık pek çok izolat bu antibiyotik grubuna karşı dirençlidir [21]. P.aeruginosa'nın etken olduğu enfeksiyonların tedavileri her geçen gün zorlaşmaktadır. Dirençli suşların çoğalması, çoklu direnç paternlerinin olması ve tedavi sırasında direnç geliştirebilme özellikleri bu bakterilere belirli bir tedavi uygulanmasını engellemektedir [22].
Hindistan'da yapılan çalışmada $\% 60$ oranında üçüncü kuşak sefalosporinlere direnç tespit edilmiştir [23]. Benzer çalışmalarda tazobaktam/piperasiline \%88 oranında direnç bulunurken gentamisine \%55 oranında direnç saptanmıştır [24]. Ülkemizde yapılan çalışmalarda Ağca'nın incelediği 495 idrar örneğinde \%10,9 oranında Pseudomonas aeruginosa üremesi tespit etmişlerdir ve en yüksek direnç gentamisin ve siprofloksasine karşı bulmuşlardır [25]. Yetkin ve ark.'nın yaptıkları çalışmada üriner sistem enfeksiyonu şikayeti ile başvuran hastalardan alınan 1312 idrar örneği sonucu retrospektif olarak analiz edilmiştir. Taranan hastaların 214 (\%16)'ünde üreme tespit edilmiştir. İdrar kültürlerinden en sık izole edilen üçüncü bakteri Pseudomonas aeruginosa 10 (\%5) olarak tespit edilmiştir. İzole edilen P.aeruginosa'lar en yüksek direnç gentamisin (\%45), aztreonam (\%40) ve seftazidime (\%34) karşı saptanmıştır [26]. Yılmaz ve ark. yaptığı çalışmada ise idrar yolu enfeksiyonu olarak tespit edilen P.aeruginosa 
izolatlarında en yüksek direnç oranı seftriakson $(\% 98,2)$, kotrimoksazol $(\% 92,9)$ ve tobramisin $(\% 67,5)$ antibiyotiklerine karşı bulunmuştur [27]. Bu çalışmada ise en yüksek direnç seftazidim $(\% 85,4)$ ve tazobaktam/piperasiline $(\% 86,6)$ karşı bulunmuştur. En az direncin görüldüğü antibiyotikler ise imipenem $(\% 20,4)$, meropenem $(\% 23,3)$ ve amikasin $(\% 15,5)$ 'dir. Çalışmamız ile diğer çalışmalar arasında direnç oranları açısından benzerlik saptanmıştır. Ayrıca çalışmamızda aminoglikozidlere karşı yıllara göre bir direnç azalması tespit edilmiştir. Bu sonucun, hastanemizde kullanılan antibiyotik tercihlerinde aminoglikozid grubunun az tercih edilmesi olduğu düşünülmektedir.

Yapılan benzeri çalışmalarda antibiyotik direnç oranların farklı olması coğrafik bölgelere, hastane florasına, hastanede kullanılan antibiyotiklere ve hastaneye yatan hasta profillerine göre değişiklikgöstermektedir. Ancakgenelolarakbakıldığında P.aeruginosa enfeksiyonlarında direnç oranları sürekli artmaktadır. Bu nedenle her hastanenin belli aralıklarla kendi antibiyotik duyarlılıklarını çıkarıp bu sonuçlara göre tedavi protokolleri oluşturması gerekmektedir. Antipsodomonal antibiyotik kullanımı ciddi psödomonal enfeksiyonlar ile sınırlı olmalıdır. Artan dirençli suşların antibiyotik profilleri ise rutin duyarlılık testleri ile değerlendirilmemeli ve bu suşlara yönelik fenotipik ve genotipik olarak direnç paternleri araştırılması gerektiği düşünülmektedir.

\section{Çıkar çatışması ve Finansman Beyanı}

$\mathrm{Bu}$ çalışmada çıkar çatışması ve finansman destek alındığı beyan edilmemiştir.

\section{Kaynaklar}

1. Pollack M. Pseudomonas aeruginosa. In: Mandell GL, Bennett JE, Dolin R. eds. Principles and Practice of Infectious Diseases. 5th edition, Elsevier, Philadelphia. 2002; 2: 2310-35.

2. Nordmann $P$, Guibert M. Extended spectrum beta-lactamases in Pseudomonas aeruginosa, J Antimicrob Chemother 1998; 42: 128-32.

3. Pier G, Ramphal R. Pseudomonas aeruginosa. In: Mandell GL, Bennett JE, Dolin R. eds.Principles and Practice of Infectious Diseases. 7th edition, Elsevier, Philadelphia. 2009; 2: 2835-60.

4. Mittal R, Aggarwal S, Sharma S, I Chhibber S, Harjai K. Urinary tract infections caused by Pseudomonas aeruginosa: A minireview. Journal of Infection and Public Health 2009; 2: 101-1.

5. Wagenlehner FM, Weidner W, Naber KG. Optimal management of urosepsis from the urological perspective. Int J Antimicrob Agents 2007; 30: 390-7.

6. Akbaş E, Zarakolu P, Aktepe OC, Tuncer A, Akbayrak A, Altınyollar $H$. İdrar yolu enfeksiyonu ön tanısı ile başvuran olgularda idrar örneklerinin mikrobiyolojik olarak değerlendirilmesi: İki yıllık bir çalışma. Mikrobiyoloji Bülteni 1997; 31: 351-61.
7. Ekinci $E$, Günay O. 12-16 yaş grubu çocuklarda atletik performansın belirlenmesinde fiziki ve kardiyorespiratuar özelliklerin etkisi. Bazı semptom ve bulguların idrar yolu enfeksiyonu tanısındaki geçerliliğinin değerlendirilmesi. E.U. Journal of Health Siences 2004; 13: 55-63.

8. Oğuz E, Kurçer Z, Sırmatel F. Harran Üniversitesi Tıp Fakültesi Araştırma ve Uygulama Hastanesi'nde yatan hastalarda antibiyotik kullanımının değerlendirilmesi. Klimik Dergisi 2000; 9: 46-8.

9. Sobel JD, Kaye D. Urinary tract infections. In: Mandell GL, Bennett JE, Dolin R (eds). Principles and Practice of Infectious Diseases (6th ed). Churchill Livingstone, Philadelphia 2005; pp 875-905.

10. Özsüt H. İdrar yolu infeksiyonları. In: Topçu AW, Söyletir G, Doganay M (editörler). Enfeksiyon Hastalıkları ve Mikrobiyolojisi (ikinci baskı). Nobel Tıp Kitabevleri, İstanbul 2002; ss 1059-70.

11. Orenstein $R$, Wong ES. Urinary tract infections in adults. Am Fam Physician 1999; 59: 1225-34.

12. Leblebicioglu $H$. Akut piyelonefrit. Üriner sistem infeksiyonu etkenleri ve antimikrobiyal duyarlılıkları. Arman D, Leblebicioglu H (editörler). Enfeksiyon Hastalıkları Tedavi Dizisi 1: Üriner Sistem Enfeksiyonlarının Tedavisi. Bilimsel Tıp Yayınevi, Ankara 2003; s 41-8.

13. Aloush V, Navon-Venezia S, Seigman-Igra Y, Cabili S, Carmeli Y. Multidrug-Resistant Pseudomonas aeruginosa: Risk Factors and Clinical Impact. Antimicrob Agents Chemother 2006; 50: 4348.

14. Grisaru-Soen G, Lerner-Geva L, Keller N, Berger H, Passwell JH, Barzilai A. Pseudomonas aeruginosa bacteremia in children: analysis of trends in prevalence, antibiotic resistance and prognostic factors. Pediatr Infect Dis J 2000; 19: 959-63.

15. Kang $\mathrm{Cl}$, Kim $\mathrm{SH}$, Park WB, et al. Risk factors for antimicrobial resistance and influence of resistance on mortality in patients with bloodstream infection caused by Pseudomonas aeruginosa. Microb Drug Resist 2005; 11: 68-74.

16. Mittal R, Aggarwal S, Sharma S, Chhibber S, Harjai K. Urinary tract infections caused by Pseudomonas aeruginosa: A minireview. J Infect Public Health 2009; 2: 101-11.

17. Basturk S. Escherichia coli, Klebsiella pneumoniae, Pseudomonas aeruginosa ve Acinetobacter baumannii suşlarında çeşitli kinolon grubu antibiyotiklerin duyarlılıklarının araştırılması. T.C. Sağlık Bakanlığı Haseki Eğitim ve Araştırma Hastanesi Enfeksiyon Hastalıkları ve Klinik Mikrobiyoloji Kliniği, Uzmanlık Tezi, İstanbul, 2005.

18. York MK: Aerobic bacteriology, "Isenberg HD (ed): Clinical Microbiology Procedures Handbook, 2.baskı" kitabında 3.1.13.18.2.21, ASM Press, Washington, DC (2007). 
19. Clinical and Laboratory Standards Institute: Performance Standards for Antimicrobial Susceptibility Testing: Seventeenth Informational Supplement, Clinical and Laboratory Standards Institute, Wayne, PA (2007).

20. Gul N, Mujahid TY, Ahmed S. Isolation, Identification and Antibiotic Resistance Profile of Indigenous Bacterial Isolates from Urinary Tract Infections Patients. Pak J Biological Sci 2004; 7: 2051-4.

21. Costerton JW, Lam J, Lam K, Chan R. The Role of the microcolony mode of growth in the pathogenesis of Pseudomonas aeruginosa infections. Rev Infect Dis 1983; 5: 867-872.

22. Arman D. Gram negatif çomak infeksiyonlarında güncel tedavi yaklaşımları. Ankem Derg 2011; 15: 421.

23. Javiya VA, Ghatak SB, Patel KR, Patel JA. Antibiotic susceptibility patterns of Pseudomonas aeruginosa at a tertiary care hospital in Gujarat, India. Indian J Pharmacol 2008; 40: 230-4.
24. Okon KO, Agukwe PC, Oladosu W, Balogun ST, Uba A. Antibiotic resistance pattern of Pseudomonas aeruginosa isolated from clinical specimens in a tertiary hospital in Northeastern Nigeria. Internet J Microbiol 2010; 8: 316-21.

25. Ağca H. İdrar örneklerinden izole edilen bakteriler ve antibiyotiklere duyarlılıkları. Kocatepe Tıp Dergisi 2011; 12: 95-100.

26. Yetkin G, Kılıç S, Söylemez H, Altunoluk B, Çalışkan A. Altı aylık periyodda üroloji klinik ve polikliniğine üriner infeksiyon ön tanısıyla başvuran hastaların semptom ve laboratuvar profili yönünden incelenmesi. A.I.B.Ü. İzzet Baysal Tıp Derg 2009; 4: 11-4.

27. Yılmaz E, Özakın C, Sınırtaş M, Gedikoğlu S. Uludağ Üniversitesi Tıp Fakültesi bakteriyoloji laboratuvarında 1999-2002 yılları arasında idrar örneklerinden izole edilen mikroorganizmalar ve antibiyotik duyarlılıkları. İnfeksiyon Dergisi 2005; 19: 91-6. 